\title{
Evaluation of Awareness and Attitudes towards Common Eye Diseases among the General Population of Northwestern Saudi Arabia
} Wareef A. Al-Lahim, Reema S. Al-Ghofaili, Hyder Mirghani , Hani ALBalawi

\author{
Faculty of Medicine, University of Tabuk, Tabuk, Saudi Arabia
}

Corresponding author : Wareef A. Al-Lahim, E-mail : allahim.w@gmail.com

\begin{abstract}
Background: Assessing of the population's awareness concerning eye diseases would provide a fundamental basis and acts as a future reference to execute health promotion initiatives. Objective: This study aimed to evaluate the public awareness and attitudes towards common eye diseases in Tabuk, Saudi Arabia.

Materials and Methods: This cross-sectional study was conducted in Tabuk, Saudi Arabia during the period from June 2017 to December 2017. A convenient sample of 397 participants of adults aged above 18 years old was chosen by a stratified method. A self-administered online survey included multiple choice and true-false questions was used to obtain information about respondent's awareness regarding common eye diseases including cataract, refractive errors, glaucoma and diabetic retinopathy.

Results: $77.6 \%$ of participants were females, $41.4 \%$ were between 18 and 25 years, $52 \%$ of the respondents had sufficient knowledge regarding common eye problems. The most frequent sources of information were the internet (46.7\%), relatives (38.5\%) and mass media (35.4\%). The participant's knowledge ranged from $66.3 \%$ for the cataract to $36.3 \%$ for refractive errors. Only educational level and job were significantly associated with knowledge about refractive errors. The majority of the respondents (75\%) reported visiting ophthalmologists only when they have complaints and just $10 \%$ of them visited ophthalmologists regularly. When they had eye problems, almost two-thirds visited the ophthalmologist directly whereas $9 \%$ and $7.4 \%$ of them did nothing or depended on home therapy, respectively. Conclusion: Awareness and knowledge of adult population in Tabuk, Saudi Arabia is suboptimal. Health education campaigns are needed to improve their knowledge and protect them from adverse complications of these diseases.
\end{abstract}

Keywords: knowledge, cataract, glaucoma, refractory errors, diabetic retinopathy.

\section{INTRODUCTION}

Visual impairment represents one of the pivotal health issues of the public with an estimated 253 million people are suffering worldwide, of which 36 million are blind. The two most leading causes are uncorrected refractive errors and then un-operated cataract ${ }^{(\mathbf{1})}$. People who are older than 50 years constitute more than $80 \%$ of visually impaired individuals. Furthermore, the prevalence of diseases with a potential effect on the eye such as diabetes mellitus sustain a tremendous increase which puts more people at a higher risk of having conditions like age-related macular degeneration, diabetic retinopathy and glaucoma ${ }^{(1,2)}$. Fortunately, vision impairment can be prevented or cured in almost $80 \%$ of conditions (1). However, insufficient awareness about sight-threatening eye diseases may contribute to the delay of seeking medical advice and losing the opportunity of timely interference and prevention ${ }^{(3)}$. Indeed, increased awareness of these conditions will likely promote effective management and consequently result in minimizing the burden of visual impairment and expense of eye care ${ }^{(4)}$.

Level of awareness regarding ocular diseases could be affected by various factors such as age, gender, education level and socioeconomic status ${ }^{(3)}$.

As reported by Waleed $\boldsymbol{e t}$ al. older people and females were more knowledgeable (5). Implementation of campaigns and community-based education programs is an influential element of eye health promotion strategies (1). Moreover, it is believed that it will not only help in raising awareness, but also encourages the community to take liability towards its eye health as well as employing available eye care services appropriately ${ }^{(2)}$.In the light of what was previously mentioned, assessing the extent of the population's awareness concerning eye diseases would provide a fundamental basis and act as a future reference to execute such health promotion initiatives.Seldom studies have been published describing knowledge, attitude and practices associated with eye diseases among the general population of Saudi Arabia ${ }^{(5,6)}$. Up to our knowledge, no such study addressed this issue among people of Tabuk city.Thus, the purpose of our study was to evaluate the public awareness and attitudes towards common eye diseases such as glaucoma cataract, diabetic retinopathy and refractive errors in Tabuk, Saudi Arabia.

\section{MATERIAL AND METHODS}

This study was conducted at the Faculty of Medicine, University of Tabuk, Tabuk city, Saudi Arabia. Tabuk city, situated in north-western Saudi Arabia, Tabuk is the provincial capital and headquarters of the Governor of the Tabuk region and it is the largest city in North Western Saudi Arabia. It has a population of 534,893 (2010 census). It is close to the Jordan-Saudi Arabia border and houses the largest air force base in Saudi Arabia. The 
study was done after approval of ethical board of University of Tabuk.

This study included a stratified sample of adult males and females aged above 18 years old of the general population of Tabuk city. Those younger than 18 years old were excluded. This was a descriptive, cross-sectional, survey-based study. The survey covered the demographic characteristics such as age, gender, level of education and occupation. Multiple choice and true-false questions were framed to obtain information about respondent's awareness regarding common eye diseases including cataract, refractive errors, glaucoma and diabetic retinopathy. The questionnaire was face validated by three consultants (Two in ophthalmology and one in community medicine. Based on the number of Tabuk city's population, 534,893 (2010 census ) and at 95\% level of confidence with an assumed precession of $5 \%$, the minimum sample size required was 384 Subjects. Data were collected using a selfadministered online survey established electronically on Google documents ${ }^{(7)}$. The study was anonymous targeting general population of Tabuk city with entire voluntary participation. The link was distributed through social networks. The script was presented in Arabic for easy understanding and convenience of the study participants. It took about 4 to 6 minutes to complete the questionnaire.

Respondents were identified and demographic data such as age, gender, level of education, and socioeconomic status and health history included chronic illnesses, personal or family history of a previous diagnosis with eye disease were collected in the first part.The second part was consisted of four main categories represented common eye diseases included cataract, glaucoma, diabetic retinopathy and refractive errors. Per each category, multiple choice and true-false questions measured the awareness of the disease. The third part assessed attitude towards eye care. Data were entered into excel sheet, then submitted for analysis.

The knowledge score was computed in the way that for each question, persons who answered correctly were given a score of one and those answered incorrectly or didn't know were given a score of zero. Then, the total score for each participant and its percentage of the total possible score were computed. Those having below 50\% (median value) of the total score were considered as having "insufficient knowledge" whereas those having $50 \%$ or more of the total score were considered having "sufficient knowledge."All the variables were summarized and reported across the study using descriptive statistics; continuous variables such as age were summarized regarding the mean and standard deviation. While, the categorical variables such as gender, level of education were summarized and reported regarding the frequency distribution. Comparisons were conducted using chisquare for binary variables. P-value less than 0.05 were considered statistical significance.

\section{RESULTS}

This study included 379 participants. Their characteristics were summarized in table 1. Age of $41.4 \%$ of them was ranged between 18 and 25 years; whereas only $2.4 \%$ of them aged over 55 years. Most of them were females $(77.6 \%)$. Almost half of them (50.7\%) were married. About two-thirds of the participants $(62.3 \%)$ had a bachelor degree. Nearly one-third of them (35.4\%) were employees and $31.9 \%$ were students. The monthly income of $44.6 \%$ exceeded 10000 SR. History of chronic disease was reported by $19.8 \%$ of the respondents. Past personal and family histories of eye diseases were reported by $58.6 \%$ and $75.7 \%$ of them respectively.

More than two-thirds of the respondents $(71.8 \%)$ knew what cataract is, $64.6 \%$ were aware that cataract affects mainly elderly population, but can affect younger population and children, $64.1 \%$ knew that cataract should be treated surgically and $64.6 \%$ were aware that cataract has a good prognosis if treated.

Almost two-thirds of the participants (67.5\%) knew the definition of glaucoma. However, only $19 \%$ were aware of the natural tendency associated with glaucoma, $45.1 \%$ were aware that untreated glaucoma could lead to loss of vision and only $7.1 \%$ knew the all three lines of glaucoma treatment (eye drops, laser and surgery).

Most of the participants (77.3\%) were aware of diabetic retinopathy and $59.1 \%$ were aware regarding the fact that diabetic retinopathy is present in stages. Most (79.7\%) of the participants were aware of the importance of following up care of diabetic retinopathy with an ophthalmologist. Only 5.3\% of the participants knew the three lines of management of diabetic retinopathy (control of diabetes, laser and eye injection). Regarding refractive errors, $64.1 \%$ of the participants knew what refractory errors were $36.7 \%$ knew that refractory errors are the commonest causes that affect vision. All types of refractive errors were known by only $2.6 \%$ of the participants and $21.4 \%$ knew all lines of treatment of refractory errors (glasses, lenses and refractive surgeries).

Overall, 52\% of the respondents had sufficient knowledge regarding common eye problems as seen in figure 1. The most frequent sources of information were the internet $(46.7 \%)$, relatives $(38.5 \%)$ and mass media (35.4\%) (Figure 2). 
The highest average percentage of knowledge levels was observed regarding cataract $(66.3 \%)$, whereas the lowest level was observed about refractive errors (36.3) (Figure 3).

Among the studied factors, only educational level and job were significantly associated with knowledge about refractive errors where the lowest level of sufficient knowledge was observed among those who had below secondary school level of education $(38.5 \%)$; whereas the highest levels were reported among those who had diploma (66.7\%) and postgraduate $(61.5 \%), \mathrm{p}=0.044$. Regarding job status, the highest level of sufficient knowledge was reported among business people $(80 \%)$ whereas the lowest level was reported among students (41.3\%), $\mathrm{p}=0.017$. Majority of the respondents $(75 \%)$ claimed that they were visiting ophthalmologists only when they have complaints and only $10 \%$ of them visited ophthalmologists regularly (Figure 4). When they had eye problems, almost two-thirds of the respondents $(65.2 \%)$ claimed that they visited ophthalmologist directly whereas $9 \%$ and $7.4 \%$ of them did nothing or used home therapy, respectively (Figure 5).

\section{Table 1: participant's characteristics $(n=379)$}

\begin{tabular}{|l|l|l|}
\hline & Frequency & Percentage \\
\hline Age (years) & & \\
$18-25$ & 157 & 41.4 \\
$26-35$ & 91 & 24.0 \\
$36-45$ & 81 & 21.4 \\
$46-55$ & 41 & 10.8 \\
$>55$ & 9 & 2.4 \\
\hline Gender & & \\
Male & 85 & 22.4 \\
Female & 294 & 77.6 \\
\hline Marital status & & \\
Single & 174 & 45.9 \\
Married & 192 & 50.7 \\
Divorced & 13 & 3.4 \\
\hline Educational level & & \\
Below secondary school & 13 & 3.4 \\
Secondary school & 68 & 17.9 \\
Diploma & 36 & 9.5 \\
Bachelor & 236 & 62.3 \\
Postgraduate & 26 & 6.9 \\
\hline Job status & & \\
Student & 121 & 31.9 \\
Employee & 134 & 35.4 \\
Not employee & 97 & 25.6 \\
Business & 5 & 1.3 \\
Retired & 22 & 5.8 \\
\hline Income (SR/month) & & \\
<5000 & 71 & 18.7 \\
5000-10000 & 139 & 36.7 \\
>10000 & 169 & 44.6 \\
\hline History of chronic diseases & & \\
No & 304 & 80.2 \\
Yes & 75 & 19.8 \\
\hline History of eye diseases & & \\
No & 157 & 41.4 \\
Yes & 222 & 58.6 \\
\hline Family history of eye diseases & \\
No & 92 & 75.3 \\
Yes & 287 & \\
\hline & & \\
\hline & & \\
\hline
\end{tabular}


Table 2: comparison between participants with and without sufficient knowledge regarding common eye diseases

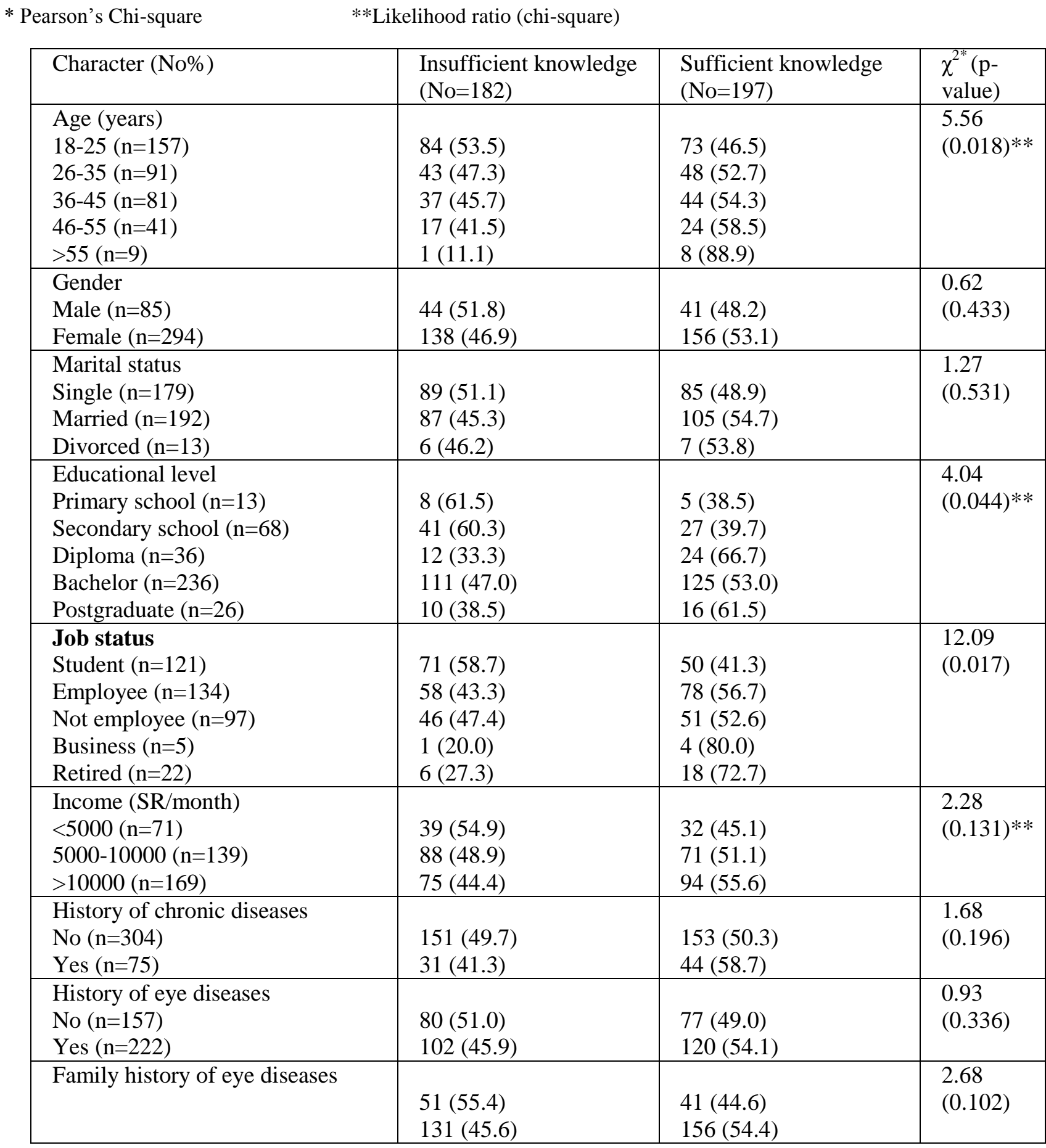




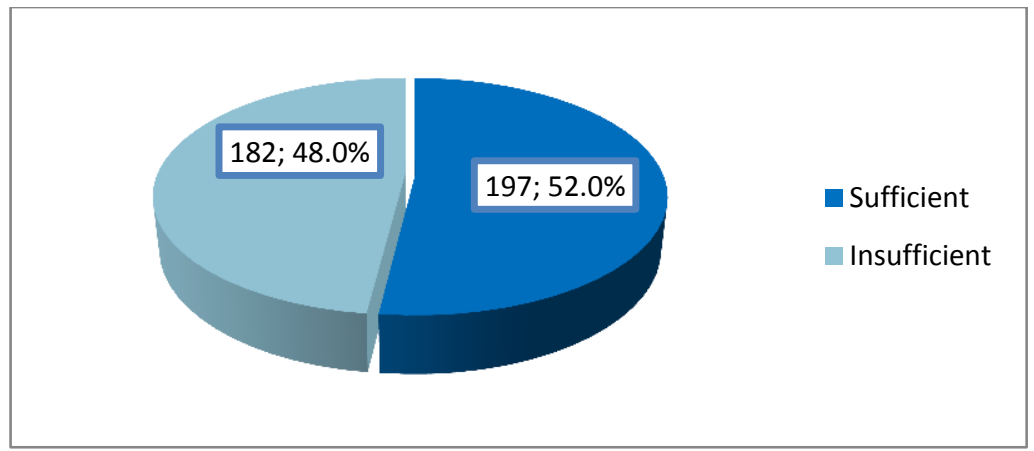

Figure 1: level of knowledge of the participants regarding common eye diseases

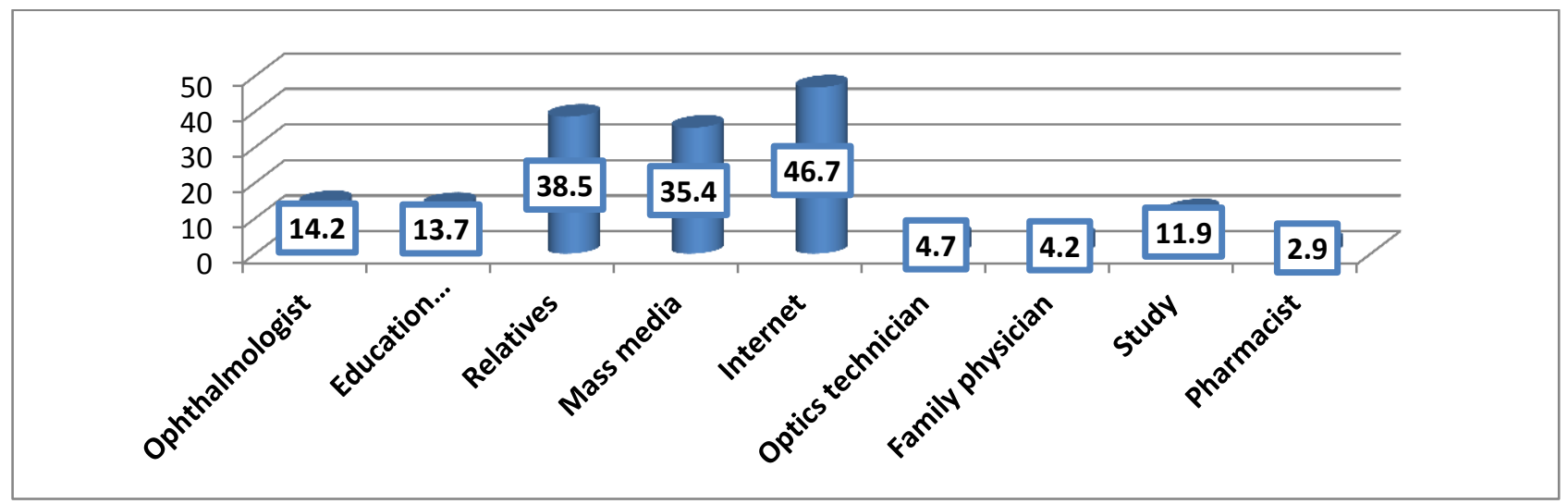

Figure 2: source of information about common eye diseases among the participants

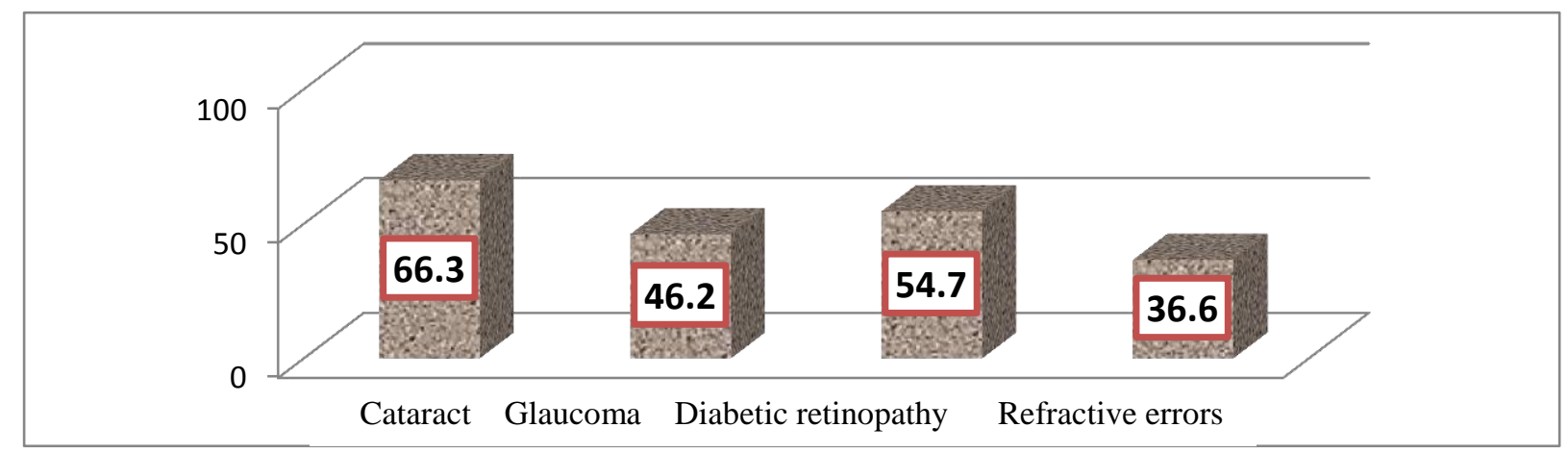

Figure 3: average percentage of knowledge levels regarding common eye diseases among the participants.

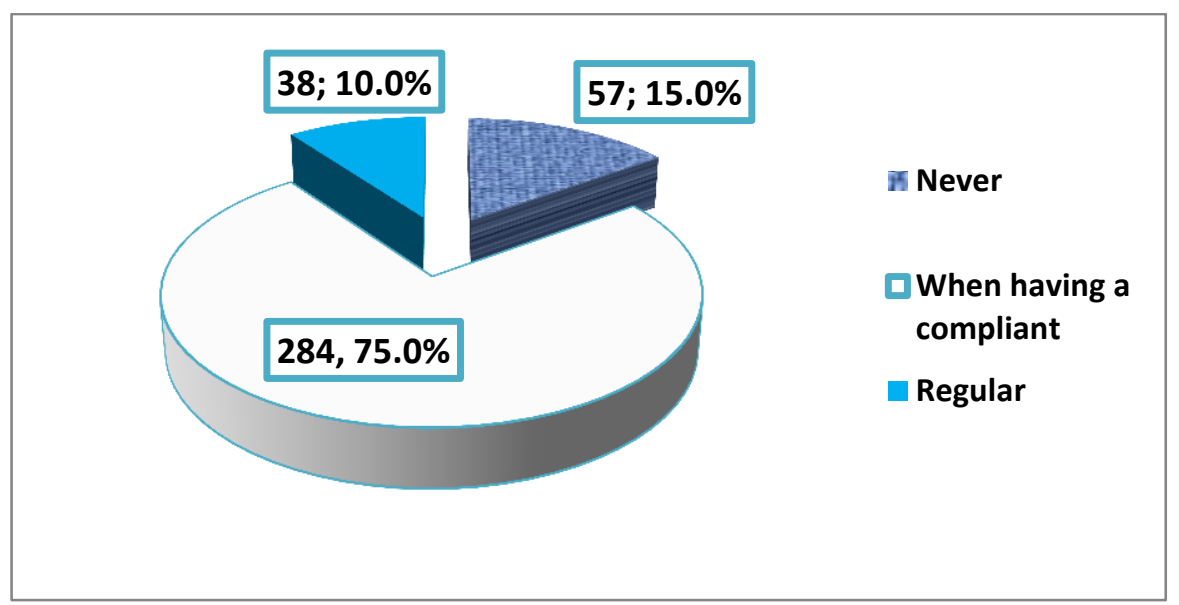

Figure 4: pattern of visiting ophthalmologist among the participants 


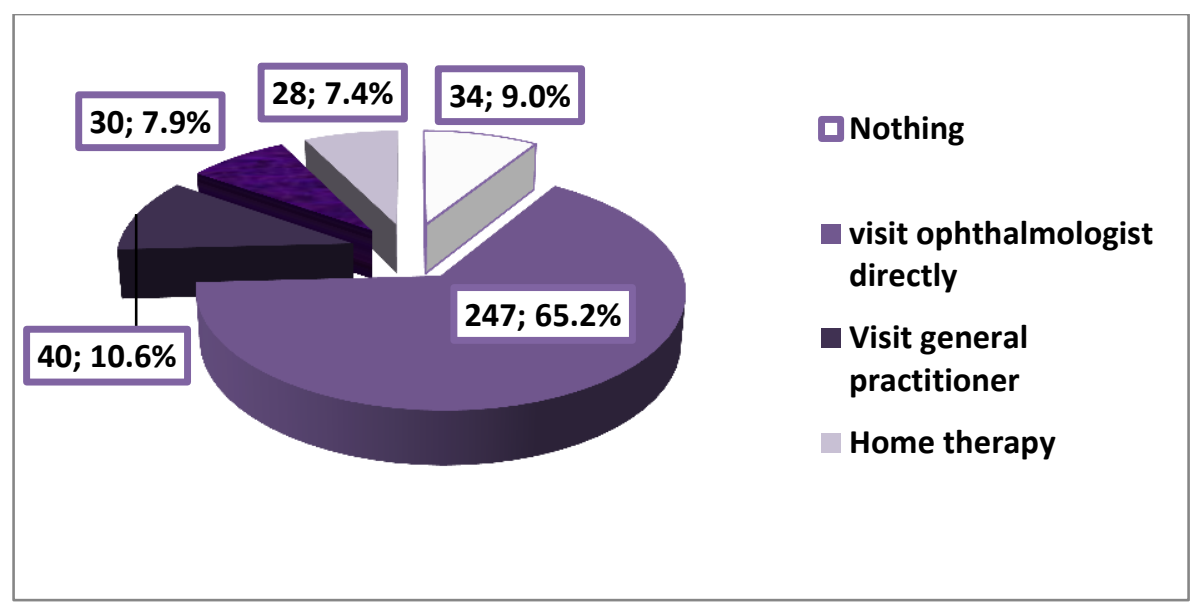

Figure 5: action done by the respondents when having an eye problem.

\section{DISCUSSION}

The burden of eye problems can be reduced to a great extent through promoting the knowledge of common eye problems among the general population (8). Therefore, this study was carried out mainly to assess the public awareness and attitudes towards common eye diseases in Tabuk, Saudi Arabia.

In the present study, $64.1 \%$ of the participants knew that cataract is treated surgically. In a similar study carried out in India, more than three-fourths of the study group knew that cataract needs surgical treatment ${ }^{(8)}$. Another study carried out in Brazil reported that $85 \%$ of the subjects were aware of the surgical treatment of cataract ${ }^{(9)}$. In Another Indian study, $71.9 \%$ of subjects accurately reported that a cataract is treated by surgery ${ }^{\mathbf{( 1 0})}$.

A study on Omani population revealed that $75.6 \%$ population was aware of cataract management ${ }^{(11)}$. On the other hand, only $18.6 \%$ of people in Takeo province in Cambodia knew about cataract operational mode of treatment ${ }^{(\mathbf{1 2})}$.

In the present study, $71.8 \%$ of the participants knew what is meant by cataract. Among non-medical Indian University students, $65.8 \%$ heard about cataract ${ }^{(13)}$. In another study carried out in South India, $69.8 \%$ of the population had an awareness of cataract ${ }^{(\mathbf{1 0})}$. In a study in Bihar (India), $73.1 \%$ of the subjects were aware of cataract ${ }^{(\mathbf{1 4})}$.

In the present study, most of the participants $(77.3 \%)$ were aware of diabetic retinopathy and even $59.1 \%$ were aware regarding the fact that diabetic retinopathy is present in stages. Also, $79.7 \%$ of the participants in the present study were aware of the importance of following up care of diabetic retinopathy with an ophthalmologist. In Southern India, $28.8 \%$ subjects were aware of diabetes retinopathy ${ }^{(4)}$. The Omani study showed that $70 \%$ of people knew about diabetic eye disease ${ }^{(11)}$. However, only $8 \%$ of the participants in the Takeo Province
(Cambodia) study had heard about diabetes and its blinding eye complications ${ }^{(\mathbf{1 2})}$. A study in Australia suggested that $78.5 \%$ of people without diabetes knew that diabetes could be sight-threatening ${ }^{(15)}$.

In the current study, $67.5 \%$ of the participants were aware of what is meant by glaucoma. However, only $19 \%$ were aware of the familial tendency associated with glaucoma, $45.1 \%$ were aware that untreated glaucoma could lead to loss of vision and only $7.1 \%$ knew the all three lines of glaucoma treatment (eye drops, laser and surgery). In India, knowledge about glaucoma and its therapy was observed in only $41 \%$ of the participants ${ }^{(8)}$. In Bihar (India), $60.3 \%$ of the subjects were not aware of glaucoma ${ }^{(14)}$. In Southern India, awareness of glaucoma was insufficient ${ }^{(4)}$. Moreover, $51 \%$ of patients with primary open-angle glaucoma were unaware of the term or nature of the disease ${ }^{(16)}$.

Concerning awareness and knowledge of refractive errors, in the present study, $64.1 \%$ of the participants knew what refractory errors are. However, only $36.7 \%$ knew that refractory errors are the commonest causes that affect vision. All types of refractory errors were known by an only minority of the participants $(2.6 \%)$ and $21.4 \%$ knew all lines of treatment of refractive errors (glasses, lenses and refractive surgeries). In another Saudi study carried out by Aldebasi among young population (15-45 years), knowledge about the different forms of optical correction of refractory errors showed a higher preference for spectacles against both contact

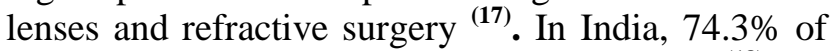
studied subjects were aware of refractive error ${ }^{(18)}$.

In general, the difference between various studies could be attributed to variation in the sociodemographic characteristics of the participants and using different tools for assessing knowledge of common eye problems. 
Wareef Al-Lahim et al.

In the present study, the highest average knowledge level was observed regarding cataract. The same has been reported by others who suggested that knowledge of cataract is better than other common eye diseases ${ }^{(\mathbf{1 9}, \mathbf{2 0})}$.As expected, education plays a prominent role in knowledge of eye diseases. The same has been reported in other studies ${ }^{(\mathbf{4}, \mathbf{2 0})}$. These studies strongly match our findings that the educational status plays a vital role in the awareness and knowledge about common eye diseases.

In the present survey, only $7.4 \%$ use home therapy for eye problems, which is lower than that reported from India where more than half of participants said that they used traditional home treatment for treating minor problems of eye ${ }^{(8)}$ and almost one quarter of the study participants $(25.7 \%)$ in a study from Bihar (India) ${ }^{(14)}$, reported using eye drops prescribed by someone other than an eye doctor.

The present study was limited mainly by its crosssectional design which proved only association and not causality and online approach which could affect the generalizability of results.

\section{CONCLUSION}

The awareness and knowledge of adult population in Tabuk, Saudi Arabia is moderate; being highest regarding cataract and lowest regarding refractory errors. Health education campaigns are needed to improve their knowledge and protect them from adverse complications of these diseases.

Authors

\section{ACKNOWLEDGEMENT}

Authors would like to thank all the participant who answered the questionnaire.

\section{FUNDING: none \\ CONFLICT OF INTEREST: none declared}

\section{REFERENCES}

1. World Health Organization (WHO)(2017):Vision impairment and blindness. Last updated October. Available : http://www.who.int/mediacentre/factsheets/fs282/en/

2. World Health Organization (WHO)(2017):Global initiative for the elimination of avoidable blindness action. Available on: http://www.who.int/blindness/Vision2020_report.pdf

3. Haddad MF, Bakkar MM and Abdo N (2017): Public awareness of common eye diseases in Jordan. BMC Ophthalmology, 17:177-183.

4. Dandona R, Dandona L, John RK, McCarty CA and Rao GN (2001): Awareness of eye diseases in an urban population in southern India. Bulletin of the World Health Organization,79(2):96-102.

$\begin{array}{lll}\text { 5. Al Rashed WA, Bin Abdulrahman AK, Zarban } \\ \text { AA, Almasri } & \text { MS, Mirza } & \text { AS }\end{array}$
KhandekarR(2017):Public awareness regarding common eye diseases among Saudi Adults in Riyadh City: a quantitative study. J. Ophthalmol., doi: $10.1155 / 2017 / 9080791$.

6. Bandar K (2016): Assessment of awareness, knowledge, attitudes and practices associated with eye diseases in the population of Aljouf and Hail Province of Saudi Arabia. Int. J. Med. Res. Prof., 2(2): 33-39.

7. Questionnaire: https://docs.google.com/forms/d/1Z8RjiPzKhFsyaoLVMn JJJdS JrAwK-3Y26b0VqqoOg/edit?usp=drive _web

8. Vaseem K, Baig VN, Rai P and Swarnkar M (2015): Awareness of eye diseases and satisfaction for eye care services in Indore, India. National Journal of Community Medicine, 6(2):370-373.

9. Temporini ER, Kara N Jr, Jose NK and Holzchuh N (2002): Popular beliefs regarding the treatment of senile cataract. Rev. Saude Publica, 36:343-349.

10. Nirmalan PK, Sheeladevi S, Tamilselvi V, Victor AC, Vi-jayalakshmi $P$ and Rahmathullah $L$ ( 2004): Perceptions of eye diseases and eye care needs of children among parents in rural south India: the kariapatti pediatric eye evaluation project (KEEP). Indian J. Ophthalmol., 52:163-170.

11. Rajiv K and Saleh A (2008): Knowledge and attitude for eye diseases and satisfaction for services among urban citizens of Oman: a pilot study. Oman Journal of Ophthalmology, 1(1):13-17.

12. Ormsby GM, Arnold AL, Busija L, Mörchen M, Bonn TS and Keeffe JE (2012): The impact of knowledge and attitudes on access to eye-care services in Cambodia. Asia. Pac. J. Ophthalmol. (Phila), 1(6):331-336.

13. Puri1 SK and Elangovan S (2016): A study of awareness and knowledge about cataract among students. Int. J. Res. Med. Sci., 4(4):1024-1026

14. Lundquist MB, Sharma N and Kewalramani K (2012): Patient per-ceptions of eye disease and treatment in Bihar India. J. Clinic Experiment. Ophthalmol., 3:213-219.

15. Livingston PM, McCarty CA and Taylor HR (1998): Knowledge, attitudes and self care practices associated with age related eye disease in Australia. Br. J. Ophthalmol., 82:780-789.

16. Quigley HA and Broman AT(2006): The number of people with glaucoma worldwide in 2010 and 2020. Br. J. Ophthalmol.,90: 262-267.

17. Aldebasi Y (2011): Young public's awareness to refractive error deficiency. Int. J. Health Sci. (Qassim), 5(1): 9-15.

18. Reddy PS (2017): Awareness and knowledge about refractive error and strabismus among general public in Southern India. All India Ophthalmology Society proceedings. Available on https://proceedings.aios.org/fp697-awareness-and-

knowledge-about-refractive-error-and-strabismus-amonggeneral-public-in-southern-india.

19. Rasheed R, Cini NV and Reena A (2017): Awareness on common blinding conditions - A population based survey. Kerala Journal of Ophthalmology, 21(1):42-46

20. Lakshmipriya K (2017): Awareness and knowledge about glaucoma and cataract in rural population and urban population. Adv. Ophthalmol. Vis. Syst., 7(5): 00237. 